\title{
Diogenes of Apollonia as a Material Panpsychist
}

\author{
Luca Dondoni ${ }^{*} \dagger+$
}

\begin{abstract}
In my paper, I shall provide a reading of Diogenes of Apollonia such that his understanding of the metaphysics of differentiation and of individual ensoulment may constitute an ingenious answer to the problems of his time. To this extent, I will argue that Diogenes' worldview solves the difficulties of Anaxagoras' metaphysics and successfully integrates mentality in a causally-closed conception of nature. Finally, I will suggest that a Diogenes-inspired approach might be relevant to treat some pressing concerns in the contemporary philosophy of mind - thus demonstrating how his production might offer some interesting solutions for the problems of our time too.
\end{abstract}

Keywords: Diogenes of Apollonia • Anaxagoras of Clazomenae • Panpsychism • Hard Problem of Consciousness • Metaphysics of mind • Presocratic Philosophy

\section{Introduction}

Often regarded as the last of the physiologoi (Barnes 1982: 20), the figure of Diogenes has been considered rather poorly by recent scholarship (Barnes 1982: 567; KRS: 427). Probably due to Aristotle's indifference towards him and his production (Met. I.984a5-7), Diogenes has always been regarded as a second-rate natural philosopher, and his output as essentially obsolete for the period he lived in (Jaeger 1947: 165). The unfortunate reputation of the philosopher might be related to the fact that, while living in Athens for a long period of his life (where he was made object of ridicule by comic poets $\left.{ }^{1}\right)$, he rejected the popular pluralist theories of Anaxagoras and Empedocles and preferred to revive the outmoded Ionian monist worldview - which was refuted well before he wrote (Graham 2006: 292). This being said, in my paper, I shall argue that Diogenes' view on the metaphysical relationship that holds between the (intelligent)

\footnotetext{
*Email address: luca.dondoni@kcl.ac.uk.; ORCID: https://orcid.org/0000-0001-8729-2859

${ }^{\dagger}$ Department of Philosophy, King's College London, London (UK).

‡ This is the final manuscript of the article which is published in Ancient Philosophy Today: Dialogoi, 3.1 (2021): 329. DOI: 10.3366/anph.2021.0040

1 The (standard) view that Diogenes was the target of Aristophanes' parody in the Clouds (Diels 1887: 1951-52) has been questioned by Fazzo (2009) and Betegh (2013).
} 
fundamental constituent of reality and the physical world constitutes an ingenious and theoretically-refined answer to the problems of his time (as it will emerge from a comparison with Anaxagoras), and possibly of our time too.

Now, the paper is roughly divided into three parts. In the first part, I will take into consideration Anaxagoras' understanding of the structure (and genesis) of the natural world and propose a reading of his fragments such that he might be seen as an advocate of a view which I shall call Coextensive dualism. In the second part, I will address Diogenes' proposed account of physical reality and argue that his view can be seen as a (successful) attempt at integrating mind in a causally-closed, unified conception of nature - a theory which I propose to call Material panpsychism. Finally, in the third part of the work, I will introduce one of the most pressing concerns in the contemporary analytic philosophy of mind (that is, the Hard Problem of Consciousness (Chalmers 1995)) and investigate whether and how a Diogenes-inspired approach may be able to solve it — or at least orient the debate in the right direction.

\section{Anaxagoras' Coextensive dualism}

\subsection{Honour thy father}

Anaxagoras' account of the natural world (together with the works of the other 'postParmenidean thinkers' (Wardy 1988: 125)) is often seen as designed to respond to the Parmenidean metaphysical challenge (cf. Lanza 1966: 1998-9; KRS: 351). Although retaining some of the central tenets of the Eleatic doctrine (e.g. the rejection of the possibility of existential change and the denial of the concept of empty space (cf. Curd 2007: 27)), it appears that Anaxagoras was essentially moved by the (anti-Eleatic) intuition that the sensible entities could not be entirely feigned (cf. Barnes 1982: 239). Thus, in order to both respect the Parmenidean canon and restore some faith in the sensible realm, he renounced the Eleatic monist ontology and posited a plurality of real substances (or basic entities) - thus shifting from a metaphysics of One to a metaphysics of Many. In this direction, in fragment 59B172, Anaxagoras seems to

\footnotetext{
2 Unless otherwise indicated, references or cross-references are to the relevant sections of Diels-Kranz (1951-2). For the fragments and testimonia of Anaximenes and Parmenides I follow Patricia Curd and Richard D. McKirahan's edition and translation (2011), while for Anaxagoras I follow Patricia Curd's edition and translation (2007), and for Diogenes of Apollonia I follow Daniel Graham's edition (2010) and Pinto (2018) for translations - with eventual modifications.
} 
be arguing that what we are presented with in ordinary life, namely the coming-into-being and passing-away of things, are not genuine processes of generation and destruction but just rearrangements of some chremata ${ }^{3}$, which are not subject to any coming-into-being or passingaway. Therefore, the objects we ordinarily interact with are not to be taken as qualifiedly real; rather they are merely temporary aggregates that emerge from the processes of mixture and separation of some natural substances.

Unlike Empedocles, Anaxagoras does not elect some of the natural substances as more original, or more existing, or again primary, than others: all the natural substances are equally real. In the extant fragments (and in testimonia), we are offered quite a few examples of the chremata. These are: air, fire (59B1); wet, dry, hot, cold, bright, dark, earth (59B4b); hair, flesh (59B10); thin, thick (59B12); cloud, water, stone (59B16). And again, from the testimonia: gold, blood, lead (59A41); white, black, sweet (59A92). Further, we are told that all the basic entities (which via mixture and separation give rise to the sensible entities of the world) once (i.e. in the pre-cosmic state) were 'together' (cf. 59B1, 59B4b). Now, from this first, rapid survey of Anaxagoras' fragments it appears that he believed that all things that exist in the Cosmos are ultimately composed of (via mixture and separation) an infinite number of natural substances or basic entities (such as hot, cold, bright, dark, but also hair, flesh etc.) and that these basic entities were originally all together as components of the original (pre-cosmic) mixture.

\subsection{Anaxagoras' (dualist) picture of physical reality}

At a first glance, by postulating an infinite number of basic entities, Anaxagoras seems to prove himself a numerical pluralist, that is, an advocate of the view that there exists a 'numerical plurality of basic entities' (Curd 2004: 64). However, at this point, he could still be a monist with regards to the kinds of entities that exist - that is, by claiming that there exists a numerical plurality of basic entities, but these entities are all of one, same metaphysical kind (e.g. physical).

This being said, from the reading of the fragments, we get the idea that the totality of the basic entities that composed the pre-cosmic mixture does not exhaust the ontological

${ }^{3}$ As it is hard to provide an exhaustive translation for the term (which has multiple occurrences in Anaxagoras), I shall leave it transliterated. This being said, in this context, I think it is safe to take term as meaning 'basic entities' (as in, the fundamental things of Anaxagoras' metaphysics) - a more detailed treatment of the notion of chrēma(ta) is offered by Naddei (1969: 98-103), Cleve (1973: 150-3), and Curd (2004; 2007: 34). 
population of Anaxagoras' metaphysics. Indeed, he posited a further, overreaching, single entity that granted unity and order to the whole system - and which is responsible for the shift from the pre-cosmic state to the actual configuration of the sensible world. In this respect, Diogenes Laertius reports what probably were the opening words of Anaxagoras' treatise: 'All things were together, and then, when Mind [vov̂s] came, it set them in order' (59A1) (cf. also 59A42). The

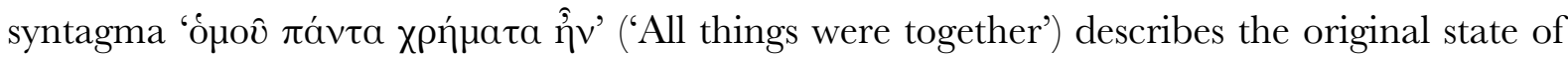
the Cosmos before Noûs initiated its rotation, thus causing the ingredients to separate and

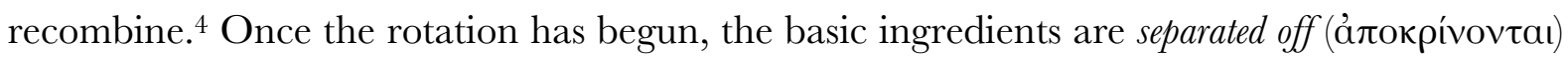
the surrounding mass and the cosmogonic process which will ultimately yield our familiar world

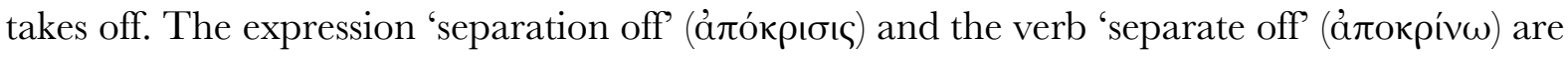
used consistently throughout Anaxagoras' production to describe (the consequences of) the action of Noûs. ${ }^{5}$ Now, I believe that the diathesis of ároкpiv $\omega$ (when used in the context of the original ingredients 'being separated off' by action of $\mathcal{N}$ ouss) is highly significant. Specifically, I

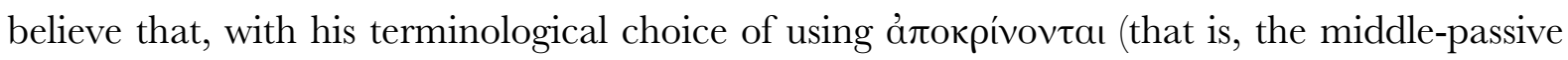
form of ả $\pi$ окрív $\omega)$, Anaxagoras intended to stress the separation out or off of the ingredients thus emphasising that the ingredients are not self-moving but are rather set in motion by action of Noûs. Thus, the diathesis of ámoкрívw might serve here as a further indication that Anaxagoras conceived of Noûs as something genuinely other than the ingredients of the original mixture (that is, as something metaphysically different from the basic entities) - and that these two utterly different entities were in some causal relationship with each other, such that the action of $\mathcal{N}$ oûs causes the ingredients to separate off.

Further corroborating evidence for the view that Noûs is distinct and yet equally fundamental as the basic entities is found in fragments 59B11 and 59B12, where Anaxagoras offers (inter alia) some indications concerning the metaphysical profile of $\mathcal{N}$ ous (in relation to the one of the ingredients of the original mixture). In 59B11, Anaxagoras puts forth the 'everythingin-everything principle' (that is, the claim that 'all things have a share of everything' (cf. 59B11)), which seems to apply to all the basic ingredients except for №ûs, which is said to be present only in 'some things' (cf. 59B11). Then, in 59B12, Anaxagoras first stresses that Noûs is not like anything else in the world and then systematically addresses its distinguishing traits. Noûs is said

\footnotetext{
4 The expression occurs also in fragments 59B1, 59B3, 59B4b, 59B6, 59B12, 59B14.

5 They appear in several fragments, namely 59B1, 59B2, 59B4a, 59B4b, 59B6, 59B7, 59B8, 59B9, 59B10, 59B12, 59B13, 59B14.
} 


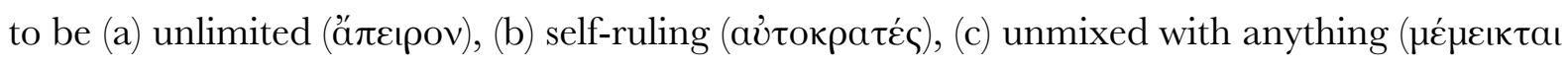

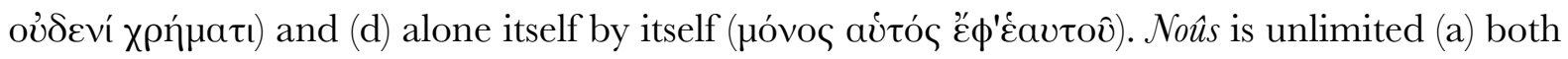
in spatial terms and in terms of power, as it pervades the whole Cosmos (I shall return on this point in Section 2.4.); it is also self-ruling (b), since it is moved by itself and by itself alone (thus, it cannot be changed by anything other than itself). The claim (c), namely that Noûs is unmixed with anything, may well be seen as a reformulation of the principle of everything-in-everything, the only exception to which is $N_{0} \hat{u}$, which does not have a share in everything but just in 'some things' (cf. 59B11). Finally, claim (d), that the Noûs is alone by itself, serves both as an emphatic conclusion of the sentence and to stress $\mathcal{N}$ oûs' logical and causal complete independence and self-reliance. All things considered, if one reads the two fragments together, one gets the idea that Anaxagoras conceived of $\mathcal{N}$ oûs as distinct $(59 \mathrm{~B} 11, \mathrm{c})$ and not needing anything prior to it to exist $(\mathrm{b}, \mathrm{d})$ - and thus as fundamental and independent. ${ }^{6}$

In sum, if we were to ask what sort of view Anaxagoras subscribed to as to what kinds of things there exist in the Cosmos, I believe it would be safe to say that he was a dualist (that is, an advocate of the theory that there are two basic kinds of things), as he posited the ingredients of the original mixture and Noûs, and conceived of them as metaphysically distinct and equally fundamental (cf. Curd 2007: 141).

\subsection{What sort of dualism?}

Let us begin by investigating the precise nature of $\mathcal{N}_{0} \hat{u}$ - - one report is particularly significant in this regard, namely fragment 59B12.

In 59B12, Anaxagoras presents Noûs as maintaining 'all discernment' ( $\gamma \omega \dot{\mu} \mu \eta)$ and as 'know(ing) ('́rvw) them all' (where 'all' stands for the things that are being mixed together, the things that are being separated off, and the things that are being dissociated). Elaborating on the use of $\gamma v \omega \dot{\mu \eta}$ and ${ }^{\prime} \gamma v \omega$, Lesher suggests that Anaxagoras conceived of Noûs as essentially characterised by some sort of capacity for intelligent decision making or practical intelligence (rather than knowledge) (1995: 131-2) (cf. also Sider 2005: 132; 137). On the other hand, Laks takes $\gamma \omega \omega \dot{\mu}$ and $\varepsilon \hat{\gamma} \gamma \omega$ more literally and argues that we should take the Anaxagorean Nous

\footnotetext{
${ }^{6}$ As is clear, the basic entities that are the ingredients of the original mixture are metaphysically independent too; yet, as they are subject to the external causal influence of Noûs, their status is not in any way comparable to the one of Noûs (cf. Curd 2007: 57).
} 
essentially as a 'critical faculty' (1993: 29), that is, as something that 'involve[s] a power of distinction or discernment' (1993: 29) — thus preferring a purely noetic reading over a practical one. All things considered, I believe that, though they sensibly diverge on what kind or aspect of intellection should be taken as prior, the two proposed accounts share one significant insight on the nature of Noûs, that is, that it is essentially a cognitive faculty (or substance) - a conclusion which is also advocated by Pinto (2017: 17). ${ }^{7}$ Thus, from the reading of 59B12, I think it is quite safe to say that Noûs is to be regarded as a bearer of some mental properties, which may well involve both a practical and a purely noetic or critical dimension — such that vov̂ৎ should be taken as a 'generic term covering all kinds of consciousness' (Laks 1993: 29).

The question now becomes: if Noûs is essentially defined in relation to mentality, what is the intrinsic nature of the elements of the original mixture (that is, of the other fundamental kind)? To this, I think it would be natural to answer: physical - such that Noûs is intrinsically mental, and the basic entities are intrinsically physical.

In sum, if my reading is legitimate, we might provide a further qualification for Anaxagoras' dualism as the view that there exist two separate, equally fundamental kinds, namely the ingredients of the original mixture and Noûs, where Noûs is intrinsically defined as a bearer of mentality, and the ingredients of the original mixture are intrinsically defined as being of physical nature. ${ }^{8}$

\subsection{Anaxagoras' account of the distribution of Mind in nature}

Having established that there is a legitimate reading of Anaxagoras' metaphysics such that there exist two fundamental kinds, namely the ingredients of the original mixture (which are essentially physical) and Noûs (which is essentially a form of mentality), it remains to clarify what

\footnotetext{
7 Against this minimal connotation of Noûs as a cognitive faculty (which seems to be common to both Lesher and Laks), Silvestre (1988) denies any noetic nor intellectual connotation to the Anaxagorean Mind — arguing that it consisted essentially and solely of a principle of movement. Silvestre's argument relies on a reading of $\gamma v \omega \dot{\mu} \mu \nu$ (in

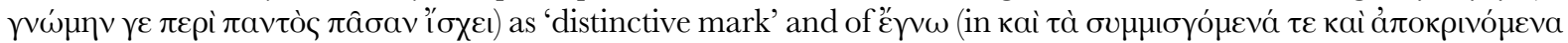

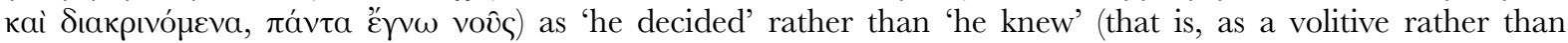
indicating a degree of knowledge). Following Laks (1993: 26), I am sceptical that, even adopting Silvestre's proposed reading, one could deny any kind of understanding or cognition to Noûs - after all, the volitive-practical dimension cannot but presuppose a certain cognitive activity (and this is also admitted by Lesher (1995: 135-42)).

8 Such a formulation approximates the classical definition of (Cartesian-fashioned) Substance dualism, as Pinto notes (2017: 16), and this might strike the reader as odd. However, the attribution of a such conceived view (which essentially sees a radical separation between mind and matter) to Anaxagoras is well attested in testimonia: 'he was the first to set mind over matter' (59A1), 'he said that matter and mind are the guardians of all things' (59A2), 'the homogeneous stuffs are the matter, and mind is the creative cause setting all things in order' (59A46).
} 
is the interplay between and the relative locations (and extensions) of these two basic kinds I shall address the two questions in order.

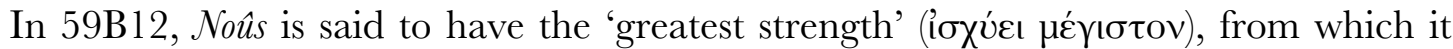
would follow that it has power over everything in the Cosmos - and this precisely in virtue of his control on the cosmic revolution. On the other hand, in the same fragment, Anaxagoras seems to suggest that Noûs' power is confined only to those things that have a soul, namely all

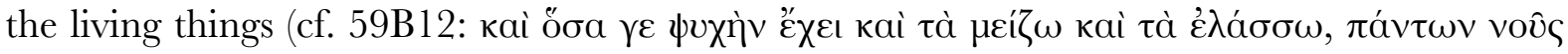

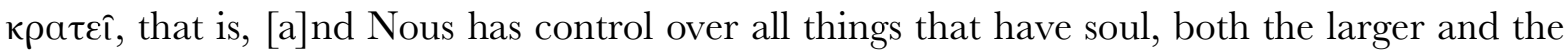
smaller) - indeed, it is dubious whether Anaxagoras did in fact envision a real separation between the Cosmic mind and the individual minds (cf. 59A58). Thus, Noûs would exert control only over those entities which are akin to itself, that is, entities endowed with a mind or reason (vov̂s) - namely, humans, animals, and also plants. ${ }^{9}$ All things considered, the point of contention here seems to be whether Noûs has power only on the living things (that is, it is $i n$ the molecules of the sole living things) or controls every molecule in the Cosmos (cf. Cleve 1973: 28). As is clear, in order for Noûs to be able to exert control on the ingredients of the original mixture, it must be present in the entirety of the mixture (cf. Pinto 2017: 16) - thus we come to the question concerning the relative locations of the two fundamental kinds. In this regard, four fragments are particularly significant, namely 59B14, 59B2, 59B12, and 59B11.

In fragment 59B14, we can read that $\mathcal{N}$ oûs is indeed present in the entirety of the original mixture (that is, in Cleve's words, that it pervades all the molecules present in the Cosmos): 'Noûs, which always is, most assuredly is even now where all the other things also are, in the surrounding multitude, and in the things that were joined together and in the things that have been separated off.' (59B14). ${ }^{10}$ In the fragment, the main claim is presented at the beginning, namely, that Noûs is 'even now where all the other things are' (that is, it pervades the entire mixture). Then, Anaxagoras proceeds to a clarification of the claim: Noûs is in 'the surrounding multitude' (i.e. the part of the mixture that surrounds our world) and in the things that have undergone separation and combination (that is, all the objects which compose our world, cf.

\footnotetext{
${ }_{9}^{9}$ On Anaxagoras ascribing plants certain mental states, see 59A117.

${ }^{10}$ I follow Sedley (2007: 20, footnote n. 58) in taking ó $\delta \dot{\varepsilon}$ vov̂s to refer to the Cosmic mind (which would explain the article), yet I read the fragment as primarily expressing a locational claim (as Pinto notes (2017: 17), the kai

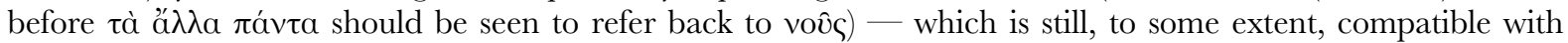
Sedley's temporal reading of the fragment.
} 
59B2). Thus, from the reading of 59B14, we get the impression that the two fundamental kinds are coextensive, that is, wherever is Noûs is also the original mixture and vice versa.

Now we come to question of the relative extensions of the two kinds. In fragment 59B2, we are told that 'air and aether are separated off from the surrounding mass' (

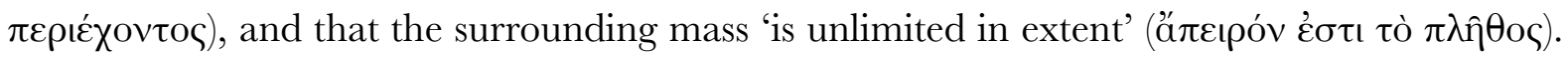
Now, the surrounding mass is certainly part of the original mixture, and, given that the surrounding mass is unlimited in extent, then also the original mixture must be unlimited in extent. This is also confirmed by 59B1, where we read that 'all things were together', but also

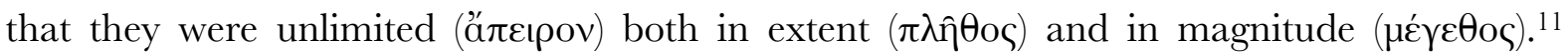

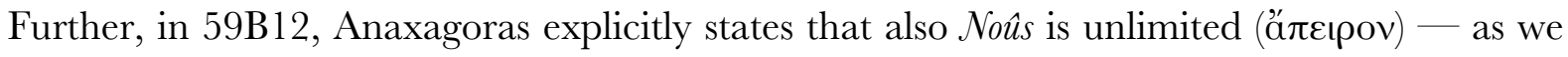
have seen in Section 2.2.. However, in 59B12 he does not qualify ámeıрov in terms of extent or magnitude (as he does in 59B1 and 59B2 with regards to the original mixture), and in 59B11 we read that 'there are some things in which Noûs, too, is present', which might be taken to suggest that there are things in which Noûs is not present — both pieces of textual evidence might be taken as an indication that Noûs and the original mixture are not, in fact, coextensive. All things considered, there seems to be no straightforward solution to the apparent inconsistency between the fragments, if not the one of trusting the explicit report of 59B14 over the mere suggestions of 59B11 and 59B12 - I shall leave the crux as it is for now and come back to it later on in relation to Diogenes. ${ }^{12}$

In sum, (if we trust 59B14 over 59B11 and 58B12,) we can say that Noûs is unlimited and so is the original mixture, and thus that, in Anaxagoras' picture of physical reality, the fundamental kind that individuates the physical is coextensive with the (only other) fundamental kind which individuates mentality — such that the latter exerts control over the former. From this we get the idea that Anaxagoras' dualism was quite peculiar, as he regarded the natural world as essentially permeated by the presence (and control) of Noûs - in one word, in Anaxagoras' dualism, Mind is everywhere.

\footnotetext{
${ }^{11}$ It is quite hard to fix a single translation for $\pi \lambda \hat{\eta} \theta$ os in Anaxagoras, as its meaning is often seen to shift in relation to the matter that is being discussed from time to time. In this direction, there has been a discussion whether $\pi \lambda \hat{\eta} \theta$ os should be taken as implying a numerical or an extensional indication (that is, as meaning 'multitude' or 'magnitude') or both (see, for example, Sider 2005: 71 and Curd 2007: 34). However, in either case, this should not cause any harm to my argument - and indeed I think Schofield (1980: 155, footnote n.5) is probably right that Anaxagoras did not have a clear-cut distinction between the two senses (at least in 59B2).

12 Pinto (2017: 18) has a solution for this. He argues that 59B11 is compatible with the two fundamental kinds being coextensive insofar one reads the claim in 59B11 as meaning that in some distinct entities Noûs is present as a distinct entity.
} 


\subsection{Coextensive dualism}

Having outlined the main tenets of Anaxagoras' view on the structure of physical reality and the distribution of Mind in the natural world, we are now in the position of providing a synthetic formulation of his worldview as a form of a

Coextensive dualism: There exist two ontologically distinct, equally fundamental kinds, such that one (i.e. in Anaxagoras, the ingredients of the original mixture) is essentially physical and the other is essentially mental (i.e. in Anaxagoras, Noûs). Although being metaphysically separate, the two fundamental kinds are both unlimited, and (thus) coextensive, such that there is no place where the physical is present and the mental is not, and vice versa.

Now, the 'Coextensive' feature tempers greatly the dualist vocation of the view (which would otherwise mimic a more familiar, Cartesian-like form of Substance dualism), however, this does not come unproblematically. Specifically, three macro-issues may be isolated as particularly unclear (and potentially harmful) in Anaxagoras' proposed account of reality.

First of all, there is a question about causation: given that the mixture and Noûs are said to be metaphysically distinct, how can Noûs causally affect the original mixture (to initiate the process of separation which would ultimately yield our familiar observable world)?

Secondly, there is the problem of the distribution of mentality in the natural world (left open by the previous paragraph): does Noûs exert control only on living things or does it really pervade every molecule in the Cosmos (that is, 58B 11 and 58B12 v. 58B 14 )?

Thirdly, there is the issue of individual ensoulment (which somewhat follows from Aristotle's perplexities at 59A55 and 59A58): granted a certain ontological continuity between Noûs (as the Cosmic mind) and the individual minds of humans, animals, and plants (that is, the 'some things' Noûs is in (cf. 59B11)), such that 'All Noûs is alike, both the larger and the smaller' (cf. 59B12), what is the difference between them (if any)?

In the next section, I shall take into consideration Diogenes of Apollonia's fragments, and argue that with his account of the structure of physical reality (and his understanding of the distribution of mentality within it) he is able to solve most of the problems from which Anaxagoras' view suffers - and that he does so by incorporating some elements of the Early Ionian monist metaphysics (aptly revised to meet the Eleatic requirements). 


\section{Diogenes' Material Panpsychism}

Diogenes is a monist for whom the basic principle is air. He seems to believe that air is the material principle that grounds the whole edifice of physical reality - along with the notion of ápxaì that Aristotle (Metaphysics, 983b2-15) attributes to the Presocratics, and in particular to the Milesians (cf. Barnes 1982: 31). Let us now try and reconstruct Diogenes' understanding of the structure of the natural world - to see how he is able to treat the three main difficulties that affect Anaxagoras' Coextensive dualism.

\subsection{The fundamental constituent and the need for an underlying nature}

To support his view about the constitutive principle, that is, that everything is ultimately made of one single kind of stuff, Diogenes offers a particular theory of change.

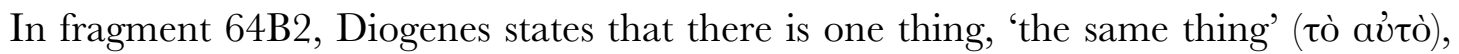
that all things are. Every thing that exists in the Cosmos, including the Empedoclean elements, is a differentiated sort of the same thing. Further, he argues that this is the case because otherwise, change and alteration would not be possible. Against the standard view that the Empedoclean elements are to be seen as the basic constituents of reality, Diogenes states that if they did not share a more basic nature, then causal interaction between them would not be possible. As Diogenes puts it, if two things were conceived of as not sharing a common nature, then they could not interact with each other. Therefore, as (we know from observation that) things in nature interact with each other, they must have a common nature.

Let us consider Diogenes' (causal) claim in connection with the modern view called Substance (or Cartesian) dualism. Substance dualism is the view that in nature there exist two metaphysically distinct kinds, namely things that are extended (i.e. body) and things that are capable of thought (i.e. mind). The view suffers from a causal difficulty (generally known as the interaction problem), which arises because the two kinds are said to be entirely conceivable one without the other. In the substance dualist's picture, mind and body do not only have distinct metaphysical natures, but one can conceive of mind as existing without the property of extension being in place - where the property of extension individuates the metaphysical kind of body - and vice versa. Therefore, if it is metaphysically possible for them to exist independently, and causation is of one kind, then it is not clear how the two substances, i.e. 
mind and body, can interact with each other. The problem is intuitively rendered by the classic 'billiard ball' example. If we conceive of causation as only by impact, one billiard ball can move another billiard ball because they both share the same metaphysical constitution, that is, they are both extended. Accordingly, if we conceive of causation as of one single kind, it is not clear how something that is not extended, i.e. mind, can causally affect something that is extended, i.e. body. As is clear, the problem is precisely that the two kinds in question lack the commonality necessary for interaction. In order for physical entities to causally interact with each other (and thus avoid the interaction problem), one must concede that the metaphysical nature of entities cannot be posited as conceivable independently from one fundamental kind. Now, if we consider Anaxagoras' Coextensive dualism, we may well see that the same problem applies. As defended in Section 2.2., Anaxagoras conceived of his two kinds (namely, the ingredients of the original mixture and $\mathcal{N} o \hat{u s}$ ) as metaphysically separate, utterly distinct, and equally fundamental - and this is more than enough for him to be exposed to a form of interaction problem.

Diogenes seems to be aware of the above causal difficulty and thus claims that a shared, primitive nature must be posited at the basis of all existing entities, and of the Empedoclean elements - such that the property of 'ontological homogeneity' serves as a necessary condition for causal interaction (cf. Graham 2006: 281). Now, I believe it is precisely due to this causal difficulty that Diogenes did not straightforwardly subscribe to Anaxagoras' dualist account of physical reality. In order to avoid the interaction problem, Diogenes resorted to the monist solution offered by the Early Ionian tradition, that is, to posit only one fundamental constituent and build the physical reality entirely out of it.

\subsection{The $\tau \rho$ ó $\pi$ ol and a theory of change}

So far, we have discussed Diogenes' idea of the need for an underlying nature (i.e. the constitutive principle), which is arguably what sets Diogenes apart from his contemporaries (i.e. Anaxagoras). Now, let us consider how Diogenes accounted for the generation (and structure) of our familiar, observable world of entities (given that all things that exist in the Cosmos are said to ultimately consist of one thing only) in a way that could meet the Eleatic constraints concerning (the denial of) quantitative change. 
Some specifications about the physical properties and the constitutive principle are provided in the first part of fragment 64B5. In accordance with what has been said for 64B2, one may be tempted to recognise in the $\tau \rho$ ó $\pi$ o (namely, at least, heat, moisture, and motion), the differentiations, that is, the different sorts that result from the process of alteration that the fundamental stuff (which is here revealed to be àǹ, 'air') undergoes - a contemporary metaphysician would call these resulting different sorts, physical properties. However, I take it that, in Diogenes' picture of reality, the $\tau$ рó $\pi$ o are not to be conceived as fully-fledged physical properties, but as axes of differentiation, where 'each of these axes offers a continuum of possible discrete values' (Pinto 2018: 5). This is to say that the $\tau \rho o ́ \pi o$ are not the actual (determinate) physical properties that we encounter in nature; rather, they are more basic (determinable) properties which administer the process of differentiation of the fundamental stuff into one particular thing and the individuation of one thing from another (cf. Graham 2006: 285). As they cannot be reduced to more fundamental properties, the $\tau \rho$ ó $\pi$ or can be said to be the most basic physical properties of Diogenes' system — such as, e.g., charge, spin, and mass (arguably) are the basic physical properties that modern physics individuates. Further, the $\tau \rho$ ó $\pi$ o are to be conceived as structural properties, that is, as the basic properties that constitute the formal (or nomic) structure of physical reality — where the fundamental stuff is the bearer of these basic properties. This is to say that, if one could individuate the exact values of heat, moisture, and motion, that a single entity exhibits, they would have the entire extrinsic profile of that entity, that is, the complete set of information on how that entity relates to the other worldly entities (or how that entity behaves in nature). ${ }^{13}$

Once having outlined the functioning of the basic, physical properties that constitute the extrinsic structure of the natural world (i.e. $\tau \rho o ́ \pi o \mathrm{~s})$, we can provide a more detailed account of the process of change. Pinto (2018: 4) notes that Diogenes' use in 64B2 of the verb

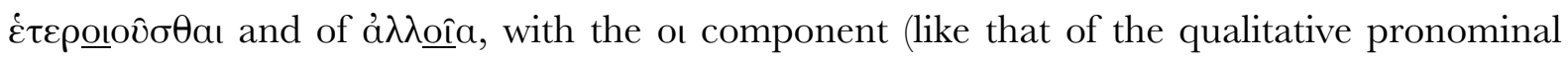

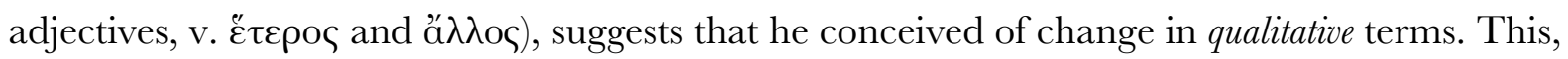
I believe, constitutes a significant feature of novelty of Diogenes' metaphysics - especially with respect to his predecessors. First of all, by quantitative change, I mean a modification explainable in terms of decrease-increase, whereas I take qualitative change to mean alteration (that

\footnotetext{
${ }^{13}$ One might read what I call the 'extrinsic profile' of an entity in light of Bird's understanding of the metaphysics of powers, and thus read the notion of extrinsic profile as meaning the nomic role that one entity (that is, a specific configuration of values on the трó $\pi$ ol) plays in relation to the other entities (cf. Bird 2007, 2012).
} 
is, a change in kind or quality). Now, Anaximenes, Diogenes' mentor, regarded density as the determining factor responsible for the individuation of the singular entities, such that '[air] differs in rarity and density according to the substances <it becomes >' (13A5). Parmenides charged Anaximenes' account of change with incoherence, for the Eleatic thought that 'nor is there any way in which what-is would be more than what-is in one way and in another way less' (28B8, 22-24) and 'not in any way greater or lesser than in another' (28B8). Anaximenes' theory of change in terms of condensation-rarefaction, that is, in quantitative terms, (together with his belief that elements were generated and could be destroyed) is thus seen to clash with the Eleatic principle of uniformity and homogeneity of what-is (Graham 2006: 288). In this direction, I think that the Apolloniate's rejection of quantitative change (conceived of as decreaseincrease), and subscription to a qualitative understanding of change (as a modification of heat, moisture, and motion), might be an indication of Diogenes' will to adhere to the Eleatic canon. ${ }^{14}$

\subsection{The fundamental constituent 'has intellection' intrinsically}

Another claim that is presented in the first part of 64B5 has to do with the attribution of vónбıৎ (intellection) to the constitutive principle. In addition to the already discussed first part of 64B5, further elaborations on the fundamental stuff having intellection (vónбıv ع̌xov, 64B5) are provided in fragments $64 \mathrm{~B} 3$ and 64B4, and in testimonium 64A19 - I shall now proceed to a joint reading of the reports in relation to the notion of intellection.

First of all, it has to be noted that, in Diogenes' picture of reality, intellection does not have the same metaphysical status of the physical properties (that is, of the configurations of values on the axes): intellection is not one of the $\tau \rho$ ó $\pi$ o neither one of the differentiated sorts. Indeed, as we understand from 64B5, vónбıৎ inheres directly in the fundamental stuff, being ontologically prior to the differentiations. This is further defended in $64 \mathrm{~B} 3$ with a teleological argument. In the fragment, Diogenes claims that, for the world to be ordered, and for the differentiation process to take place, the fundamental stuff must have intellection - and thus

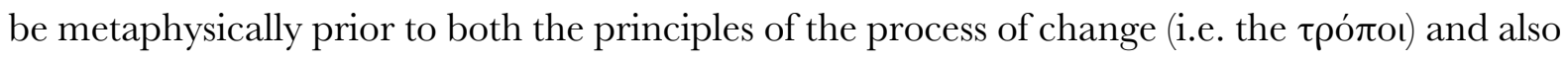
the results of said process (i.e. the different sorts).

\footnotetext{
${ }^{14}$ It should be stressed that, in order to emend Anaxagoras' theory of nature, Diogenes did not simply implement the Milesian monism, but actively modified the latter to make it compatible with the Parmenidean metaphysical requirements (via the notion of $\tau \rho \operatorname{sos}_{\text {) }}$ - thus saving Material monism from the criticisms that were advanced against it by the Eleatics (and that rendered the Early Ionian tradition essentially obsolete).
} 
A second significant point is that, in Diogenes' picture, it follows for the metaphysical claim that every thing that exists in the Cosmos (ultimately) is air (that is, from the monist structure of the view), that the order cannot be imparted by another, separate entity: the capacity to order the world must be immanent to air itself (as the fundamental constituent) and this further testifies to Diogenes' rejection of any Anaxagorean-like dualism. In this direction, one notable aspect of the first part of fragment 64B5 (which I take to constitute significant evidence in support of my proposed reading) has to do with Diogenes' choice of the term vónбıৎ (intellection), and not vộৎ (intelligence), to refer to the fundamental constituent. Employing vónбıৎ, the activity (or 'function' (Laks 2008: 358)), and not vôิৎ, the faculty (or 'substance' (Laks 2008: 358)), might suggest that air is actively engaging in intellection whereas with vov̂s this would not be ensured, as a faculty can be enacted or not (cf. Pinto 2018: 9). Now, I believe that the terminological choice matches with the overall picture of physical reality that Diogenes is drawing. Due to his strict monism, Diogenes' air cannot be seen as a substance distinct from everything else (rather it is the very constituent of everything that exists), thus the choice of the term vónбıs, as indicating the activity and not the faculty of intellect, aims at emphasising that the activity of air is immanent to the world - and not affecting (or better, causing) the process of differentiation from a separated, privileged standpoint, as in Anaxagoras (cf. Laks 2008: 358).

This being said, the most pressing question for the purposes of this paper concerns what vónбıৎ should be taken to mean - given that it cannot be seen as a separate substance. Accordingly, Laks claims that the most 'important point' (2008: 358) of Diogenes' thought is the link between the fundamental constituent and the 'noetic activity' (2008: 358) it is characterised by. From the reading of the fragments, air seems to be capable of thought, and thinking might be seen as the primary activity it is engaged in - and this reading is also silently suggested by Barnes, when he claims that air 'bestows thought' (1982: 462). Further indications on the nature of vónбıৎ might come from testimonium 64A19, where it is reported that

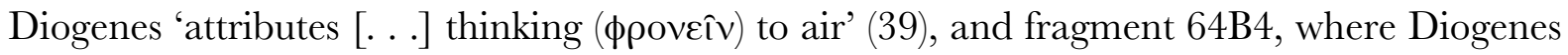
is said to have believed that air was 'the source' ( (vónбıv) in animals and human beings. Now, following Laks (1993: 28-29), I believe one can propose to read Diogenes' vónбıৎ on a par with Anaxagoras' Noûs, that is, as referring to a form of mentality, taken in broad terms (thus involving a cognitive, practical, and possibly perceptual dimension) - with the crucial difference (as already stressed) that Diogenes did not conceive 
of vónбıৎ as a separate, distinct substance. All things considered, I think it is safe to take air as the ultimate bearer of some mental properties (that is, properties that pertain to mind or even consciousness $^{15}$ ), and to take these mental properties to constitute the intrinsic nature of air - such that air bears these properties essentially.

Now, once established that vónбıৎ is a mental property (or a set of mental properties) and that the fundamental constituent bears this property essentially, one still has to clarify in what sense air can be said to be inherently engaged in intellection - as vónбıৎ cannot be a separate substance, as per Diogenes' monism (v. Anaxagoras' Coextensive dualism). Let us adopt an atomist framework, for illustrative reasons. We might speculate that the single bits (or atoms) of air (everything is ultimately composed of) may be extrinsically defined by their physical properties (i.e. the state of the $\tau \rho$ ó $\pi \mathrm{ol}$ ), which determine their behaviour in the natural world (as defended in Section 3.2.); while they are intrinsically defined by their being engaged in intellection (and other mental properties), that is, taken in and of themselves, they are bearers of mental properties. ${ }^{16}$ As is clear, it is hard to imagine what it would mean for an atom to think (that is, to bear mental properties essentially), but, given Diogenes' framework, it is not inconceivable. ${ }^{17}$

\subsection{Material panpsychism}

We have seen how according to Diogenes every thing that exists in the Cosmos is ultimately made of air, and air is inherently thinking. From this, bearing in mind what has been said for Anaxagoras' views, we can formulate a synthetic definition for Diogenes' worldview as an instance of

\footnotetext{
${ }^{15}$ Attempting to account for the use of vónбıc in 64B5, Jaeger suggests the translation 'consciousness': '[ . . .] they all have different degrees of vónбıৎ (consciousness?)' (1947: 246). This being said, as 'consciousness' is a considerably loaded term (especially in the contemporary debate), I will prefer the much more cautious 'mentality' to qualify Diogenes' vónбıৎ (as already done with Anaxagoras' Noûs) — more on this in Section 4.

${ }^{16}$ I am aware that the couple extrinsic/intrinsic might be confusing (especially when applied to ancient contexts), thus I propose to read it in connection with the much more codified distinction between dispositional and categorical properties - where extrinsic would correspond to dispositional, and intrinsic to categorical. In this direction, dispositional properties individuate the nomic role one entity plays in relation with the other entities (cf. Bird 2007, 2012) and categorical properties are those which identify one entity for what it really is, taken in and of itself (cf. Armstrong 2005; Heil 2012).

${ }_{17}$ Crucially, we ought not to think that the mind of a single bit (or atom) of air would have the same structural complexity of the one of an animal or human being. As we shall see later on (in Section 3.5.), according to the Material panpsychist, the degree, quality, and kind of intelligence (or consciousness) one entity (can) possess is dependent upon the physical properties that that entity bears.
} 


\begin{abstract}
Material panpsychism: There exists only one thing (i.e. in Diogenes, air), the same thing (all things ultimately consist of), and there are two ways one can look at this one thing. From an extrinsic point of view, the one thing bears some physical

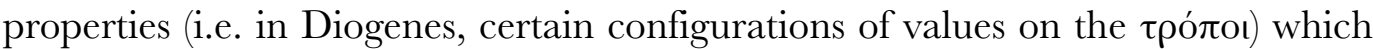
determine how one particular entity behaves in relation to the other entities. From an intrinsic point of view (that is, taken in and of itself), the one thing is defined in virtue of its bearing some mental properties. Thus, mentality is realised at the fundamental level of reality (i.e. it constitutes the intrinsic nature of the fundamental constituent) and is ubiquitous in the natural world.
\end{abstract}

The difference between Coextensive dualism and Material panpsychism should be quite evident. On most of dualist views (including Anaxagoras'), mind and matter are seen as separate substances, while in Material panpsychism mental and physical are two aspects of (or ways of looking at) the same thing (that is, the fundamental constituent) — such that mentality provides ground for materiality (by constituting the intrinsic nature of the fundamental stuff).

Now, Material panpsychism solves most of the problems of Anaxagoras' Coextensive dualism - and does so by integrating the Early Ionian monist metaphysics (aptly reshaped in view of the Eleatic requirements by means of the mechanism of the $\tau \rho$ ó $\pi \mathrm{ol}) .{ }^{18}$ First of all, the problem of the (causal) relationship between the two fundamental kinds from which Anaxagoras' view suffered does not affect Material panpsychism. Indeed, Diogenes' is a monistic view according to which everything in the Cosmos is essentially (constituted by) one thing, and thus it does away with the division in two fundamental kinds (and so with the interaction problem). Secondly, the problem of distribution of mentality in the natural world is also solved. By positing vónбıৎ as the primary activity the fundamental constituent is engaged in (thus making mentality the intrinsic nature of the fundamental stuff), Diogenes can safely say that consciousness is ubiquitous in the natural world - without renouncing the concrete reality of the physical nor making mentality non-fundamental and derivative. All things considered, it seems that there is still only one issue left on the table, that is, the question about individual ensoulment - and I propose to explore Diogenes' treatment of individual minds using as a foil the traditional form of panpsychism.

\footnotetext{
${ }^{18}$ It is precisely to stress the continuity with the Ionian School (whose followers are often referred to as Material monists) that the term 'Material' has been chosen to qualify Diogenes' theory.
} 


\subsection{Diogenes' account of the distribution of mind in nature}

As we have seen, from my reading of his fragments, Diogenes may be said to be a panpsychist, that is, an advocate of the view that mentality is fundamental and ubiquitous in the natural world. Accordingly, Barnes identifies a clear panpsychist thread in the Appolloniate's production and holds that '[o]n the orthodox view of Diogenes' philosophy, [. . .] material monism becomes a form of pantheism' (1982: 460). This being said, as appears manifest from my formulation of the view, I believe that Diogenes' Material panpsychism is not the canonical form of panpsychism - and this emerges as particularly relevant when one considers his approach to the issue of individual ensoulment. In this section, I will thus briefly outline what panpsychism is traditionally taken to be (which is what I suspect Barnes was thinking of when attributing the view to Diogenes), see how the traditional panpsychist would reply to the question of the distribution of mentality in the physical world (that is, the question of which and how many entities are endowed with a soul), and clarify how Diogenes' version of panpsychism diverges from the traditional one on the issue of individual ensoulment.

\subsubsection{Traditional panpsychism}

The term 'panpsychism' derives from the aggregation of the words $\pi \hat{\alpha} v$, meaning 'all', and фvхท́, primarily meaning 'soul' but also translated as 'mind' (cf. KRS: 95; Sassi 2018: 112). Many variations of the theory have been put forth in the tradition, especially in recent years, such that it is often difficult to provide a unique and all-encompassing definition of the position. David Chalmers defined it as the view that 'everything is conscious' (1996: 216) or that 'everything has a mind' (298). More closely to the ancient roots of the theory, Popper and Eccles stated that panpsychism is the view that 'everything has a soul, or [...] a rudiment of a soul' (1977: 15). Now, I believe a satisfactory formulation of the (canonical version of the) view would be something along these lines:

Traditional panpsychism: Every thing has a soul, either one of its own or a share in a world-soul, independently from the physical properties the entity bears.

Now, given that Traditional panpsychism might appear quite an unusual view, let us say a few words on why one would want to support it in the first place. The advantages of the view are 
best expressed in causal terms, as suggested by Sedley (2007). If every thing that exists in the Cosmos has a soul, and soul is the principle of motion, then one can provide a causally-closed picture of reality. On the other hand, the main weakness of this form of panpsychism, as is manifest, has to do with its counter-intuitivity (cf. KRS: 97). Consider, for example, Thales' doctrine of soul. From a joint reading of testimonia 11A22a, 11A1, and 11A22b, Thales is said to have conducted a universal induction from the isolated cases of magnets and pieces of amber being ensouled (as they can produce motion without being themselves moved) to all the existing entities in the Cosmos (cf. e.g. Jaeger 1947: 21; Graham 2010: 41). The main thought here is that one may well accept that magnets and amber have souls, and that this accounts for their capacity to move themselves and other objects, but extending the ensoulment to other nonmotive stones, that is, entities that do not display any motive capacity, (and indeed to all existing entities,) seems unjustified and unreasonable.

\subsubsection{Diogenes' theory of individual ensoulment}

As I have anticipated, I do not believe that Diogenes' Material panpsychism may be said to be equivalent to Traditional panpsychism. Now, in order to demonstrate that Diogenes was not a Traditional panpsychist, it would be sufficient to show that, in his account, not all entities possess a unified, singular mind, but, still, that mentality is ubiquitous and fundamental in the natural world. However, this is not so simple a task, as from the reading of the fragments we are presented with some sort of dilemma. On the one hand, intellection is not itself one of the

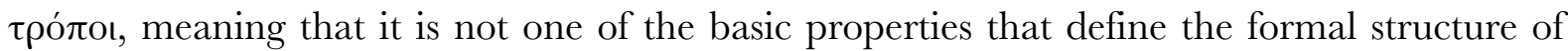
physical reality, rather it is prior to them. From this it follows that the state of the $\tau \rho$ ó $\pi$ o should not affect the presence or not of intellection, as the latter is ontologically more primitive. This is to say that the particular configuration of values of heat, moisture, and motion one entity exhibits does not preclude it possessing intellection, as intellection is realised on a more primitive level - and this seems to go plainly in the direction of Traditional panpsychism. On the other hand, Diogenes seems to suggest that, despite being ultimately constituted of air, entities such as plants, statues, and other worldly objects do not engage in intellection (cf. 64A19). How can this be possible? Pinto (2018: 13-14) offers a possible solution to the impasse. He proposes to separate one entity having intellection 'taken as a whole' and 'every bit' of the entity having intellection. Following Pinto's lead, we can say that for every bit of an entity to 


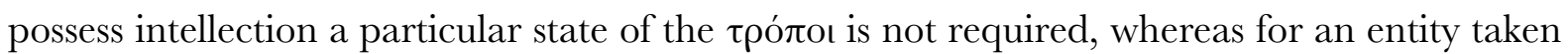
as a whole to possess a singular process of intellection, some structure (i.e. a certain configuration of physical properties) is needed.

Let us now apply this theoretical framework to the study of the relationship between air (as the fundamental constituent) and the mechanism of ensoulment, as it is addressed by Diogenes in the second part of fragment $64 \mathrm{~B} 5$ and in 64B6. One option to make sense of the view is to hold that, even though for incredibly simple things, such as the single bits the worldly objects are ultimately constituted of, the possession of intellection is simply granted by air being intelligent, for complex objects, such as human beings, something more is required, namely, the circulation of air throughout the body. In this direction, one way to read Diogenes' doctrine of the soul (in $64 \mathrm{~B} 4$ and $64 \mathrm{~B} 6$ ) is to take that, in order for an entity to have a soul, and thus a singular process of intellection, it must exhibit a physical structure that allows warm air to circulate throughout the body - and when this circulation stops, the premises for intellection ceases to exist, and the individual dies (cf. 64B4). If we follow my reconstruction, the account of circulation provided in 64B6 appears completely consistent with what we can read in the second part of 64B5. Indeed, the apparatus that enables the circulation process is, as is clear, due to the differentiations (meaning that it is a specific configuration of physical properties), and thus different entities, with different apparatuses, have different degrees of intelligence: 'living things are multiform and many and not like each other in appearance, way of life, or intelligence because of the multitude of the differences' (64B5). Finally, the last line of the fragment re-states (and draws attention to) the general premise upon which the whole discourse on circulation and distribution of intelligence is predicated: all things can engage in intellection only because they are ultimately constituted of air, which is inherently endowed with intellection.

In sum, we can say that, with regards to individual ensoulment, Material panpsychism is the view that mentality is realised at the fundamental level of reality and is ubiquitous in the natural world; however, for an entity to have a unified mind, some physical conditions have to be met. ${ }^{19}$ In this way, the metaphysics (that is, the functioning of the $\tau$ рó $\pi$ ot and the theory of change) and the philosophy of mind (that is, the distribution of intelligence in the natural world and the doctrine of soul) are reconciled into one coherent worldview.

\footnotetext{
${ }^{19}$ It should be noted that Material panpsychism retains all the causal benefits of the traditional version of the view, while not being affected by the counter-intuitiveness problem from which Traditional panpsychism suffers - as the Material panpsychist does not (have to) claim that literally every thing that exists in the Cosmos has a singular process of intellection (i.e. a unified mind).
} 


\section{Material panpsychism, Russellian monism, and the Hard Problem of Consciousness}

In this final section, I would like to push further and suggest that Diogenes' Material panpsychism can provide some relevant insights for one of the concerns that are currently at the centre of the debate in the contemporary (analytical) philosophy of mind and metaphysics, that is, the Hard Problem of Consciousness - and thus show how his worldview might offer some interesting solutions for the problems of our time too.

The Hard Problem concerns the place of mind within our metaphysical story of reality (cf. Chalmers 1995), and, generally speaking, arises from the intuition that physical stuff and mental stuff do not really seem to belong together. Traditionally, three candidates have been put forth to solve the enigma. First of all, one might elaborate on what David Papineau calls the 'dualist intuition' (2002) and thus claim that mind and matter are utterly distinct and that, even though they are closely correlated, they are essentially irreducible one to the other - this view is generally referred to as dualism. Alternatively, one might think that, as we can be certain only of the reality of consciousness (that is, of our own experience and mental life), one should not posit matter as mind-independent — this would be the idealist solution. However, in each of the two solutions, something of our story of the world is irremediably lost: the dualist picture is a radically fragmented one, while we should aspire to a unified conception of nature; the idealist picture is a sceptical one, while we should aspire to preserve some trust in the observerindependent reality of the external world. In this direction, a third candidate has gained increasing influence in the past century and has now imposed as the dominant view in contemporary philosophy of mind (cf. Field 1972: 357; Stoljar 2010: 13): physicalism. The physicalist roughly believes that, at the fundamental level of reality, there exist only purely physical entities (cf. Stoljar 2015) - this of course does not mean that mental phenomena do not exist, but they are seen as essentially derivative.

Now, in the past 15 years, the rediscovery of Bertrand Russell's and Arthur Eddington's 1920's writings, together with the appearance of some compelling arguments against physicalism (namely, Jackson's Knowledge argument (1982, 1986) and Chalmers' Conceivability argument $(1996,2009))$, led to the development of an anti-idealist monistic view which is now known as Russellian monism - and of which I argue (if my reading is legitimate) Diogenes' 
Material panpsychism is the eminent forefather. Generally speaking, Russellian monism can be defined as the view that at the fundamental level of reality there exist some inscrutable properties of a single kind, properties which provide ground for physical entities and consciousness alike (cf. Kind 2015, 404). ${ }^{20}$ The contemporary advocates of the view believe that the Russellian monist theory might be successful where the dualist and the physicalist paradigms failed, that is, in providing a convincing account of the human mind within a unified conception of nature (Goff 2017: 18). Let us now consider the main tenets of Russellian monism and compare the view with Material panpsychism - to find out if the initial intuition of a kinship between the two is confirmed.

Following Alter and Nagasawa (2015: 425), we can render Russellian monism as the conjunction of three claims:

1. Structuralism about physics: the basic properties physics describes are structural or relational or extrinsic properties.

2. Realism about inscrutables: there are inscrutables [i.e. properties which ground the structures/relations physics describes], the nature of which are not wholly extrinsic/structural/relational.

3. Phenomenal foundationalism: at least some inscrutables are phenomenal properties.

Let us now examine the premises, one by one, and see if they are compatible with the Material panpsychist's worldview.

The first premise states that the explanatory power of physics ${ }^{21}$ is restricted to only structural/relational/extrinsic properties, that is, to those properties which are fully accountable for using a purely quantitative language (cf. Goff 2017: 30-31). As we have seen,

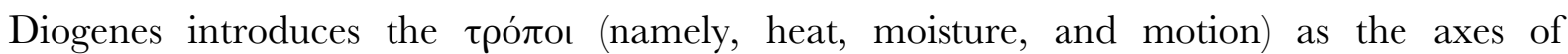
differentiation that regulate the process of individuation of singular entities. The $\tau \rho$ ó $\pi$ o thus serve in Diogenes' picture of reality as the most basic physical properties that may be found in

\footnotetext{
20 The term 'inscrutables' is not ideal, as it has manifest epistemological connotations which are secondary with respect to the sense in which it is used, which is purely ontological (as also admitted by Alter and Nagasawa 2015: 425, footnote n. 9). As we shall see presently, the 'inscrutable properties' (or simply 'inscrutables') are those fundamental properties which constitute the ground of reality - and are deemed inscrutable precisely because they exceed the domain of enquiry of physical science.

${ }^{21}$ In this context we should take physics in a very broad and nuanced sense, roughly as 'observation'.
} 
the natural world - such as the modern physicist takes charge, mass, and spin to be the basic physical properties of their system. Now, the physical properties that we encounter in nature can thus essentially be seen as configuration of values on the axes of differentiation, i.e. the

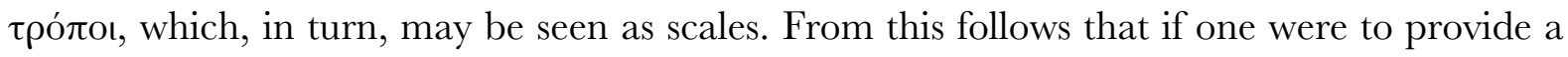
full description of a particular entity (in terms of the physical properties that that entity bears), they could simply individuate the values that entity exhibits on the axes - that is, the entity's particular temperature, the value of its moisture, and how stationary or swift that entity is. By doing so, they would have a full description of the extrinsic profile of the entity at issue. Thus, the description of the entity would consist of the set of values that pick that particular entity out of the set of the totality of the entities that populate the Cosmos. If this is true, then the description that would result from this process would be entirely quantitative, as it would consist precisely of the values that particular entity corresponds to on the axes. ${ }^{22}$ All things considered, then, I believe that Structuralism about physics is perfectly in line with the Material panpsychist's

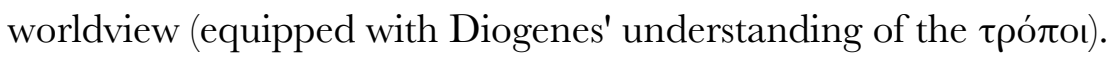

Premise 2 of Russellian monism claims that other than the structural/relational properties that physics describes, there are some additional properties whose nature is not wholly structural/relational. As already said, physics accounts only for the physical properties, that is, (in the context of Diogenes' metaphysics) those properties which result from the process of differentiation. However, all the physical properties are grounded in the fundamental stuff, as all the things that exist in the Cosmos are ultimately constituted of 'the same thing' (i.e. air) (cf. 64B2). Now, as per Diogenes' proposed theory of change, as it is by definition ontologically prior to the physical properties, the fundamental stuff cannot be characterised using physical terms (Barnes 1982: 462). In turn, as argued in Section 3.3., it seems that the fundamental constituent might be essentially characterised as being engaged in vónбıৎ — and indeed that vónбıৎ constitutes the intrinsic nature of air as the fundamental constituent (that is, it characterises what air is, taken in and of itself). If this is true, then there are some properties which cannot be fully accounted for by means of the quantitative language of physics, namely those properties which inhere directly to the fundamental stuff — and (at least one of) these properties is vónбıc. All things considered, Realism about inscrutables does not only seem compatible with Diogenes'

22 Note that the term 'quantitative' is here used in a different way from how it was employed in Section 3.2.. In Section 3.2., I used 'quantitative' to characterise Anaximenes' understanding of change as involving a decreaseincrease dynamic, while here with 'quantitative description' I simply mean an account that is developed entirely (and solely) by means of the mathematico-nomic language of physical science. 
worldview, in fact, it seems to follow from his conception of the relationship between 'the same thing', 'the different sorts', and 'vónбıs'.

If the first two premises may be seen to be in line with Diogenes' metaphysical picture of reality, the third one (that is, Phenomenal foundationalism) is certainly the most problematic. First of all, one has to clarify what 'phenomenal properties' are. Most of the advocates of Russellian monism (cf. e.g. Seager 1995, Alter \& Nagasawa 2015, Goff 2017), in order to pin down what is to be taken as a phenomenal property, or a phenomenal state, appeal to Thomas Nagel's notion of what-it-is-like-ness (1974) and hold that a mental state is phenomenally conscious if there is something it is like to be in that state. In this direction, pain is a phenomenal property inasmuch there is something it is like for an entity to be in pain - thus phenomenal properties address the qualitative aspect of experience. As is clear, it would be absurd to argue that Diogenes had in mind the notion of phenomenal consciousness, or even that he was hinting at something nearly similar, when he was talking about vónбıs. However, in complete fairness, Bertrand Russell and Arthur Eddington, often referred to as the forefathers of Russellian monism, did not have the notion of (Nagelian) phenomenal properties either - and yet they genuinely believed that some kind of mentality was fundamental and ubiquitous in the natural world. If we follow this line of thought, and we bear in mind what has been said for the Anaxagorean Noûs and Diogenes' vónбıৎ (that is, that they should be taken in broad terms to cover 'all kinds of consciousness' (Laks 1993: 29), thus including a cognitive, practical, and possibly perceptual dimension), we can say that Phenomenal foundationalism may be compatible with Diogenes' thought - as vónбıৎ, which inheres directly to the fundamental stuff (that is, constitutes the intrinsic nature of the fundamental constituent), is essentially a form of mentality.

Now, Russellian monism (just like Material panpsychism) solves the Hard Problem by conceiving of mentality as the intrinsic nature of matter - thus avoiding both making mind alternative to the physical (as in dualism) or dispensing of it as derivative (as in physicalism). As there is no such thing as completely mindless matter (i.e. mentality is a fundamental and ubiquitous feature of physical reality), then the opposition that is central to the mind-body problem collapses and the problem does not arise in the first place. Further, both views avoid the undesirable drawback of Traditional panpsychism, as it does not follow from either Russellian monism or Material panpsychism that all physical entities have a fully-formed, individual centre of consciousness (or an individual process of intellection) - as shown in Section 3.5. 
In sum, if my arguments are sound, then there might be individuated a substantial continuity between Diogenes' understanding of physical reality and the place of mentality within it (i.e. Material panpsychism) and the view which is now known as Russellian monism. This is not merely to say that, in some sense, Diogenes of Apollonia should be counted, among Russell and Eddington, as one of the forefathers of the view (which currently constitutes the most prominent candidate available to solve the Hard Problem of Consciousness). More importantly, if my reading is legitimate, as Material panpsychism is better equipped to respond to the mind-body problem than the competitors (namely, dualism and materialism), then Diogenes of Apollonia should be rightfully seen as an innovator and his views should be given a much higher consideration than the scholarship recognised. ${ }^{23}$

\footnotetext{
${ }^{23}$ Some acknowledgements are in order. First of all, I would like to thank my supervisor at King's, Professor Raphael Woolf, and my term tutor, Professor Joachim Aufderheide, for their invaluable guidance. A thanks goes also to all the participants to the 13th Brown University Mark Shapiro Annual Philosophy Conference and the members of the KCL-UCL Ancient Greek Philosophy Seminar. I would also like to thank Professor Philip Goff, Dr. Giacomo Giannini, Professor Franco Ferrari, Professor Luca Vanzago, Referees A and B, and Jonathan Griffiths for their feedback, objections, and comments. Finally, a special thanks goes to Alesia Preite, without whose support this paper would have never seen the light.
} 


\section{Bibliography}

Alter, T.; Nagasawa, Y. (2015) 'What Is Russellian Monism,' in Consciousness in the Physical World, edited by T. Alter and Y. Nagasawa, New York: Oxford University Press.

Armstrong, D. (2005) 'Four disputes about properties', Synthese 144, 309-320. Barnes, J. (1982) The Presocratic philosophers, London-Boston: Routledge and Paul.

Betegh, G. (2013) 'Spoofing Presocratic Arguments', in Socrate et les "Presocratiques" dans les Nuées d'Aristophane, edited by A. Laks and R. Saetta Cottone, Paris: Editions Rue d'Ulm.

Bird, A. (2007) 'The regress of pure powers?', Philosophical Quarterly 57, 513-34.

(2012) 'Monistic dispositional essentialisms', in Properties Powers Structures, edited by A. Bird, B. Ellis, and H. Sankey, New York: Routledge.

Chalmers, D. (1995) 'Facing up to the problem of consciousness', Fournal of Consciousness Studies 2, 200 -19 .

(1996) The Conscious Mind, Oxford: Oxford University Press.

(2009) 'The Two-Dimensional Argument against Materialism', in Oxford Handbook of the Philosophy of Mind, edited by B. McLaughlin, Oxford: Oxford University Press.

Cleve, F. M. (1973) The Philosophy of Anaxagoras: An Attempt at Reconstruction, The Hague: Martin Nijhoff.

Curd, P. (2004 [1998]) The Legacy of Parmenides: Eleatic Monism and Later Presocratic Thought, Princeton, NJ: Princeton University Press; Las Vegas: Parmenides Publishing.

(Ed.) 2007. Anaxagoras of Clazomenae: Fragments. Text and Translation with Notes and Essays, Toronto: University of Toronto Press.

Curd, P.; McKirahan, R. D. (Eds.) (2011) A Presocratics Reader: selected fragments and testimonia, Indianapolis: Hackett Pub. Co..

Diels, H (1887) 'Leukippos und Diogenes von Apollonia', Rheinisches Museum fïr Philologie 42, 1-14.

Diels, H.; Kranz, W. (1951-1952) Die Fragmente der Vorsokratiker, Berlin: Weidmann.

Eddington, A. (1928) The Nature of the Physical World, Cambridge: Cambridge University Press.

Fazzo, S. (2009) 'Diogene di Apollonia e le Nuvole di Aristofane: nota intorno alle origini di un problema storiografico', Aevum Antiquum 9, 161-169.

Field, H. (1972) 'Tarski's Theory of Truth', Journal of Philosophy 69, 347-375.

Goff, P. (2017) Consciousness and Fundamental Reality, New York: Oxford University Press.

Graham, D. W. (2006) Explaining the Cosmos: The Ionian Tradition of Scientific Philosophy, Princeton: Princeton University Press.

(Ed.) 2010. The Texts of Early Greek Philosophy. The Complete Fragments and Selected Testimonies of the Major Presocratics, Cambridge: Cambridge University Press.

Heil, J. (2012) The Universe As We Find It, Oxford: Oxford University Press.

Jackson, F. (1982) 'Epiphenomenal Qualia', Philosophical Quarterly 32, 127-36.

(1986) 'What Mary Didn't Know', Journal of Philosophy 83, 291-5.

Jaeger, W. W. (1947) The theology of the early Greek philosophers, Oxford: Clarendon Press.

Kind, A. (2015) 'Pessimism about Russellian Monism', in Consciousness in the Physical World, edited by T. Alter and Y. Nagasawa, New York: Oxford University Press. 
Kirk G. S., Raven J. E., \& Schofield M. (1983) The Presocratic Philosophers, Cambridge: Cambridge University Press. [KRS]

Lanza, D. (1966) Anassagora: Testimonianze e Frammenti, Florence: La Nuova Italia.

Laks, A. (1983) Diogene d'Apollonie, Paris: Lille.

- (1993) 'Mind's Crisis: On Anaxagoras' Noñc', Southern Fournal of Philosophy 31, 19-28.

(2008) 'Speculating about Diogenes of Apollonia', in The Oxford Handbook of Presocratic Philosophy, edited by P. Curd and D. W. Graham, Oxford: Oxford University Press.

Lesher, J. H. (1995) 'Mind's Knowledge and Powers of Control in Anaxagoras DK B 12', Phronesis 40,125-42.

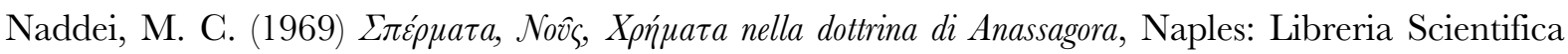
Edizioni.

Nagel, T. (1974) 'What is it like to be a bat?', Philosophical Review 83, 4, 435-450.

Papineau, D. (2002) Thinking about Consciousness, Oxford: Oxford University Press.

Pinto, R. (2017) 'Nous, Motion, and Teleology in Anaxagoras', Oxford Studies in Ancient Philosophy 52, 132.

(2018) 'Air as Noēsis and Soul in Diogenes of Apollonia', Phronesis 62, 1-24.

Popper, K.; Eccles, J. (1977) The Self and Its Brain, New York: Springer.

Russell, B. (1927) The Analysis of Matter, London: Kegan Paul.

Sassi, M. (2018) The Beginnings of Philosophy in Greece, Princeton-Oxford: Princeton University Press.

Schofield, M. (1980) An Essay on Anaxagoras, Cambridge: Cambridge Univerisity Press.

Seager, W. (1995) 'Consciousness, Information, and Panpsychism', in Explaining Consciousness: the Hard Problem, edited by J. Shear, Cambridge, MA: MIT Press.

Sedley, D. (2007) Creationism and Its Critics in Antiquity, Berkeley: University of California Press.

Sider, D. (Ed.) (2005) The Fragments of Anaxagoras, Sankt Augustin: Academia Verlag.

Silvestre, A. M. (1988) 'Significato e Ruolo del Nous nella Filosofia di Anassagora', Il Contributo 12, $29-52$.

Stoljar, D. (2010) Physicalism, New York: Routledge. (2015) 'Physicalism', Stanford Encyclopedia of Philosophy.

Wardy, R. (1988) 'Eleatic Pluralism', Archiv fü Geschichte der Philosophie 70, 125-46. 